\title{
Is Neutrophil/Lymphocyte Ratio A Useful Marker to Predict the Severity of Pre-Eclampsia?
}

\author{
Abd-Alazim M¹, Ashraf H Mohammad ${ }^{1}$, Mohammad S Radwan², Ahmed A Shokr ${ }^{1}$
}

\author{
${ }^{1}$ Department of Obstetrics and Gynecology and ${ }^{2}$ Department of Clinical Pathology, Faculty of \\ Medicine, Al-Azhar University, Cairo, Egypt \\ Corresponding author: Ahmed A Shokr, Email: dr.ah.shoker@gmail.com
}

\begin{abstract}
Background: Preeclampsia refers to the new onset of hypertension and proteinuria or hypertension and end-organ dysfunction with or without proteinuria after 20 weeks of gestation in a previously normotensive woman.

Objective: This study was aimed to evaluate the relationship between Neutrophil/Lymphocyte ratio (NLR) in patients with pre-eclampsia (PE) and severity of preeclampsia. Subjects and methods: This prospective study comprised a total of 150 pregnant females divided in 3 groups " 50 healthy pregnant females (Group 1), 50 females with mild pre-eclampsia (Group 2) and 50 with severe pre-eclampsia (Group 3)". All the study participants were statistically compared in respect to Neutrophil/Lymphocyte Ratio (NLR) and the baseline data including age and BMI. Results: Maternal NLR was determined to be significantly high in the pre-eclamptic patients (Groups 2 and 3) compared to those with healthy pregnancies (Group 1$)(\mathrm{p}=0.0003)$. NLR was significantly higher in the severe pre-eclampsia group than in the mild pre-eclampsia group $(p=0.042)$. Conclusion: It could be concluded that while NLR was determined as significantly high in patients with pre- eclampsia, to be able to use this in the classification of the severity of pre-eclampsia, there is a need for further studies on a more extensive population.
\end{abstract}

Key words: Leukocytes, Neutrophils, Neutrophil/Lymphocyte ratio, Pre-Eclampsia.

\section{Introduction}

Preeclampsia refers to the new onset of hypertension and proteinuria or hypertension and end-organ dysfunction with or without proteinuria after 20 weeks of gestation in a previously normotensive woman. Severe hypertension "systolic blood pressure is $\geq 160 \mathrm{mmHg}$ or diastolic blood pressure is $\geq 110 \mathrm{mmHg}$ " or signs/symptoms of end-organ injury "with Systolic blood pressure $\geq 140 \mathrm{mmHg}$ or diastolic blood pressure $\geq 90 \mathbf{m m H g}$ " represent the severe end of the disease spectrum ${ }^{(\mathbf{1})}$.

Pregnancy is a controlled inflammatory state. It is believed that an excessive systemic inflammatory response is the basis of the clinical manifestations of PE (2).

Maternal circulating leukocytes are activated in pregnancy and further activated in preeclampsia $^{(3)}$.

Oxidized lipids are potent activators of neutrophils, leading to expression of cyclooxygenase-2 (COX-2) which regulates the release of thromboxane, TNF and superoxide $^{(4)}$.

Neutrophils are usually thought to be the first line of defense against infection at the site of a wound, but as has been reported in recent studies, neutrophils also infiltrate systemic vascular tissue in women with preeclampsia, thus causing vascular inflammation ${ }^{(5)}$.

Maternal neutrophil/lymphocyte ratio has come into current use to predict preeclampsia ${ }^{(6)}$.

This study was aimed to evaluate the relationship between Neutrophil/Lymphocyte ratio (NLR) in patients with pre-eclampsia (PE) and severity of preeclampsia.

\section{Patients and Method}

This prospective study included a total of 150 pregnant females attending at the Obstetrics and Gynecology Department of Mansoura General Hospital. Approval of the ethical committee and a written informed consent from all the subjects were obtained. This study was conducted between April 2017 and April 2018.

The 150 pregnant females were divided in 3 groups "Group 1: 50 healthy pregnant females (the control group), Group 2: 50 pregnant females with mild preeclampsia and Group 3: 50 pregnant females with severe preeclampsia".

Every case was selected as an Egyptian pregnant woman after 20 weeks of 
gestation seeking medical advice at Mansoura General Hospital.

$$
\text { Exclusion criteria included }
$$

established heart disease, chronic hypertension, known diabetes, renal or hepatic dysfunction, cancer, alcohol or drug abuse, thyroid disorders, hematological disease, ongoing infection or systemic inflammatory conditions, or any autoimmune disease, any medication related to inflammatory condition of patient such as corticosteroids, patients with any pregnancy complication like membrane rupture or intrauterine fetal Death (IUFD) or multiple pregnancies.

All patients were subjected to clinical evaluation and investigations workup needed to make sure that they met with their group. These included: Complete history, complete physical examination; blood pressure measurement " with Hypertension to be defined as average systolic blood pressure $\geq$ $140 \mathrm{~mm} \mathrm{Hg}$ or average diastolic blood pressure $\geq 90 \mathrm{~mm} \mathrm{Hg}$ or use of antihypertension medications.

Investigations included urine protein, $\mathrm{CBC}$, renal and liver function tests. Proteinuria is defined as Protein $\geq 1+(30 \mathrm{mg} / \mathrm{dL})$ on a paper test strip dipped into a fresh, clean voided midstream urine specimen or $\geq 0.3 \mathrm{~g}$ protein in a 24-hour urine specimen.

We calculated neutrophil lymphocyte ratio "NLR" values for all patients, with neutrophil and lymphocyte values obtained from corresponding $\mathrm{CBC}$, by dividing the absolute neutrophil by the absolute lymphocyte values.

\section{Statistical analysis}

In order to investigate how NLR level is related to severity of preeclampsia, Statistical comparison was made between the control group and all the preeclampsia patients in respect of NLR and the baseline data including age and BMI.

The collected data were revised, organized, tabulated and statistically analyzed using statistical package for social sciences (SPSS) version 20.0 for windows (SPSS Inc., Chicago, IL). Data were presented as mean \pm standard deviation (SD), frequency, and percentage. Continuous variables were compared using Student t test "independentsamples t test" (two-tailed). A receiver operating characteristic (ROC) curve analysis was used to determine the optimum cut-off level for the NLR value that best correlate with the severity of pre-eclampsia. The level of significance was accepted if the $\mathrm{P}$ value < 0.05 .

Results

One hundred and fifty pregnant women were included in the study. Patients were divided into three groups based on preeclampsia. The baseline demographic and hematological data of the patients according to the groups is presented in (Table 1).

Table (1): Patients' characteristics as a comparison between normal and preeclamptic pregnant women

\begin{tabular}{|c|c|c|c|c|c|}
\hline & & $\mathrm{N}^{\odot}$ & Mean & Std. Deviation & P value \\
\hline \multirow[t]{2}{*}{ Age (years) } & NORMAL & $\overline{50}$ & 26.80 & 5.15 & \multirow[t]{2}{*}{0.88} \\
\hline & PREECLAMPSIA & 100 & 26.94 & 5.82 & \\
\hline \multirow[t]{2}{*}{ Gravida } & NORMAL & 50 & 2.84 & 1.60 & \multirow[t]{2}{*}{0.25} \\
\hline & PREECLAMPSIA & 100 & 2.56 & 1.30 & \\
\hline \multirow[t]{2}{*}{ Parity } & NORMAL & 50 & 1.48 & 0.99 & \multirow[t]{2}{*}{0.26} \\
\hline & PREECLAMPSIA & 100 & 1.30 & 0.90 & \\
\hline \multirow{2}{*}{$\begin{array}{l}\begin{array}{l}\text { Gestational age at delivery } \\
\text { (weeks) }\end{array}\end{array}$} & NORMAL & 50 & 37.92 & 1.51 & \multirow[t]{2}{*}{0.039} \\
\hline & PREECLAMPSIA & 100 & 37.30 & 1.82 & \\
\hline \multirow[t]{2}{*}{ BMI $\left(\mathrm{kg} / \mathrm{m}^{2}\right)$} & NORMAL & 50 & 22.87 & 3.60 & \multirow[t]{2}{*}{0.109} \\
\hline & PREECLAMPSIA & 100 & 23.99 & 4.20 & \\
\hline \multirow[t]{2}{*}{ Neutrophils $\left(10^{9} /\right.$ liter $)$} & NORMAL & 50 & 7.7934 & 2.72 & \multirow[t]{2}{*}{0.001} \\
\hline & PREECLAMPSIA & 100 & 9.6360 & 3.25 & \\
\hline \multirow[t]{2}{*}{ Lymphocytes $\left(10^{9} /\right.$ /iter $)$} & NORMAL & 50 & 2.8196 & 0.93 & \multirow[t]{2}{*}{0.002} \\
\hline & PREECLAMPSIA & 100 & 2.3528 & 0.79 & \\
\hline \multirow[t]{2}{*}{ NLR } & NORMAL & $\overline{50}$ & 3.2183 & 1.98 & \multirow[t]{2}{*}{0.0003} \\
\hline & PREECLAMPSIA & 100 & 4.7132 & 2.47 & \\
\hline
\end{tabular}


Table (2): Patients NLR as a comparison between normal and preeclamptic pregnant women.

\begin{tabular}{|c|c|c|c|c|c|}
\hline & & $\mathrm{N}^{\odot}$ & Mean & Std. Deviation & P value \\
\hline \multirow[t]{2}{*}{ 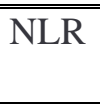 } & "NORMAL & 50 & 3.2183 & 1.98595 & \multirow[t]{2}{*}{0.037} \\
\hline & MILD & 50 & 4.2138 & 2.67660 & \\
\hline \multirow[t]{2}{*}{ NLR } & NORMAL & 50 & 3.2183 & 1.98595 & \multirow[t]{2}{*}{0.000} \\
\hline & SEVERE & 50 & 5.2126 & 2.16805 & \\
\hline \multirow[t]{2}{*}{ NLR } & MILD & 50 & 4.2138 & 2.67660 & \multirow[t]{2}{*}{0.042} \\
\hline & SEVERE & 50 & 5.2126 & 2.16805 & \\
\hline
\end{tabular}

Table (1) shows that the patients with pre-eclampsia were more likely to have higher neutrophil counts and NLR values. In contrast lymphocyte counts were lower in patients with pre-eclampsia. The gestational age at cesarean section was statistically significantly earlier in patients with preeclampsia than normal pregnant women $(\mathrm{p}=0.039)$. No significant differences in maternal age, gravidity, parity or BMI were observed between groups.

Table (2) shows that the mean NLR value of the pre-eclampsia group was significantly higher than the control group $(\mathrm{p}=$ 0.001 ) and further significantly higher in severe pre-eclampsia group than mild one $(\mathrm{p}=$ $0.042)$.

In ROC analysis, "NLR value $=3.28$ " had sensitivity $=70 \%$ and specificity $=68 \%$ in comparison between pre-eclamptic patients and normal pregnant group. While in comparison between mild and severe preeclamptic groups, "NLR value $=4.77$ " had sensitivity $=58 \%$ and specificity $=70 \%$.

\section{Discussion}

This study was undertaken as a trial to investigate the relationship between the severity of preeclampsia and NLR that can be measured by a simple complete blood count.

NLR combines the predictive risk of two leukocyte subtypes "neutrophils and lymphocytes" into a single risk factor ${ }^{(7)}$.

It was suggested to be an indirect indicator of systemic inflammation in various recent studies. Moreover, raised NLR was demonstrated to be a predictor of major adverse cardiovascular events in acute myocardial infarction, peripheral arterial occlusive disease, and coronary artery disease (8).

In the current study, There was a significantly high Neutrophil Lymphocyte
Ratio in patients with preeclampsia compared to those with healthy pregnancies $(\mathrm{p}=0.0003)$.

The number of neutrophils was higher in circulation of preeclamptic patients as compared to normal pregnant women $(\mathrm{p}=$ 0.001) with Lymphocyte count, on the other side, higher in normal pregnant women than in preeclamptic patients, with a significant difference $(p=0.002)$ which may simply describe the significantly high NLR in preeclamptic patients.

In addition, when the comparison was made more specific, NLR was found to be significantly higher in the severe preeclampsia group compared to the mild preeclampsia group which suggests that NLR could predict the severity of preeclampsia $(\mathrm{p}=0.042)$.

This observation is similar to that reported by Lurie et al. who found that the absolute neutrophil count was significantly elevated in preeclamptic patients compared with that of control subjects with an uncomplicated pregnancy. The elevation in neutrophils was more prominent in patients with severe preeclampsia compared with those with mild preeclampsia. The absolute lymphocyte and eosinophil counts declined in patients with preeclampsia compared with the uncomplicated pregnancies, whereas the monocyte and basophile counts did not differ (9)

Oylumlu et al. reported that a significantly higher NLR values was observed in the preeclampsia group compared to the control group $(7.3 \pm 3.5$ versus $3.1 \pm 1.1 ; \mathrm{p}<$ $0.001)^{(6)}$.

On the other side, while the NLR level was also found to be significantly higher in the group with preeclampsia than in healthy control subjects in another study, NLR was not found to be sufficient in the determination of the severity of preeclampsia in the preeclamptic patients. However, it was emphasized that NLR could be useful in the 
determination of preeclampsia in high-risk pregnancies ${ }^{(\mathbf{1 0})}$.

The cutoff point of NLR to distinguish preeclampsia from normal pregnancy in our study was "NLR $=3.28$ " with "sensitivity $=$ $70 \% "$ and "specificity $=68 \%$ ".

In case of comparison between mild and severe preeclampsia, the cutoff point of NLR was "NLR $=4.77$ " with "sensitivity $=$ $58 \%$ " and "specificity $=70 \%$ ".

When all this findings is taken together, the findings of the current study together with those of previous studies, the use of maternal NLR levels could be a useful marker in detection of $\mathrm{PE}$ and subsequent determination of the severity of preeclampsia.

\section{Limitation}

Unfortunately, our study had some limitations. The major limitations were being a single-centre study and the relatively small study population. So for further studies regarding this issue "NLR and severity of preeclampsia", we recommend a multicenter study with a large number of population followed through the study.

\section{Conclusion}

In conclusion, while NLR was determined as significantly high in patients with preeclampsia, and significantly higher in those with severe preeclampsia than those with mild preeclampsia, NLR is promising as a marker for the detection of PE and subsequent determination of severe preeclampsia and further supporting trials are needed to support results of this study.

\section{References}

1. American College of Obstetricians and Gynecologists, Task Force on Hypertension in Pregnancy (2013): Hypertension in pregnancy. Report of the American College of Obstetricians and Gynecologists' Task Force on Hypertension in Pregnancy. Obstet Gynecol., 122:1122.

2. Roveri-Querini P, Castiglioni MT, Sabbadini MG and Manfredi AA (2007): Signals of cell death and tissue turnover during physiological pregnancy, pre-eclampsia, and autoimmunity. Autoimmunity,40: 290-294
3. Gervasi MT, Chaiworapongsa T, Pacora P, Naccasha N, Yoon B, Maymon $E$ and Romero $R$ (2001): Phenotypic and metabolic characteristics of monocytes and granulocytes in preeclampsia. Am. J. Obstet. Gynecol., 185: 792-797

4. Vaughan J, Walsh $S$ and Ford G (2006): Thromboxane mediates neutrophil superoxide production in pregnancy. Am. J. Obstet. Gynecol.,195: 1415-1420

5. Shah $T$ and Walsh $S$ (2007): Activation of NF-kappa B and expression of COX-2 in association with neutrophil infiltration in systemic vascular tissue of women with preeclampsia. Am. J. Obstet. Gynecol., 196 :48.e1-48.e8

6. Oylumlu M, Ozler A, Yildiz A, Oylumlu M, Acet H, Polat N, Soydinc HE, Yuksel $M$ and Ertas F (2014): New inflammatory markers in pre-eclampsia: echocardiographic epicardial fat thickness and neutrophil to lymphocyte ratio. Clin. Exp. Hypertens.,36: 503-507

7. Tamhane U, Aneja S, Montgomery $D$, Rogers E, Eagle $K$ and Gurm $H$ (2008): Association between admission neutrophil to lymphocyte ratio and outcomes in patients with acute coronary syndrome. The American journal of cardiology, 102(6):653-657.

8. Erturk M, Cakmak HA, Surgit O, et al. (2014): Predictive value of elevated neutrophil to lymphocyte ratio for longterm cardiovascular mortality in peripheral arterial occlusive disease. J Cardiol;64(5):371-376.

9. Lurie S, Frenkel $\mathbf{E}$ and Tuvbin $\mathbf{Y}$ (1998): Comparison of the differential distribution of leukocytes in preeclampsia versus uncomplicated pregnancy. Gynecologic and obstetric investigation, 45(4): 229-231. 
Abd-Alazim M et al.

10. Kurtoglu E, Kokcu A, Celik H, Tosun $M$ and Malatyalioglu E (2015): May ratio of neutrophil to lymphocyte be useful in predicting the risk of developing preeclampsia? A pilot study. The Journal of MaternalFetal \& Neonatal Medicine, 28(1): $97-$ 99. 